\title{
Alcohol consumption in pregnancy. How much is safe?
}

\author{
P J M DAVIS, J W PARTRIDGE, AND C N STORRS \\ Paediatric Department, Warneford Hospital, Leamington Spa, Warwickshire
}

SUMMARY Nine hundred and seventy-three white women attending an antenatal clinic completed a questionnaire on parity, social class, smoking habits, and consumption of alcohol and coffee. Forty-nine per cent said they were non-drinkers and none of their babies had a major congenital abnormality; whereas $1.2 \%$ of the babies of the women who did consume alcohol had major abnormalities. The babies of women who said they drank more than an average of $20 \mathrm{ml}$ alcohol a day had significantly smaller head circumferences than the babies of non-drinkers in some gestational age groups. Maternal serum $\gamma$-glutamyltransferase levels predicted abnormal fetal outcome in the 3 women in whom they were raised. There is no safe level of alcohol consumption in pregnancy and even moderate 'social' drinking is associated with abnormal fetal outcome.

There is a substantial risk of the fetal alcohol syndrome in the offspring of women drinking the equivalent of $90 \mathrm{ml}$ absolute alcohol daily (5-6 hard drinks). ${ }^{1}$ Pregnant women consuming half that amount have an increased risk of having an infant born preterm, or one below expected birthweight, length, and head circumference, or with major and minor congenital abnormalities. ${ }^{2}$ It has not been established if moderate 'social' drinking has any adverse effect on the fetus. We report the results of a survey of nearly 1000 pregnancies.

\section{Methods}

During 1980, all white women attending the booking clinic at the Warneford Hospital, Leamington Spa, were invited to complete a self-administered questionnaire, marked only with the patient's hospital number. The study was closed when 1000 completed questionnaires had been received, 1120 women having been invited to participate. Data were collected on social class, smoking, and consumption during pregnancy of various beverages including coffee and alcoholic drinks. The women were also asked about 'binge' drinking of alcohol in pregnancy (excessive alcohol consumed on isolated occasions, as opposed to regular consumption of alcohol). Alcohol consumption was expressed as $\mathrm{ml}$ of absolute alcohol equivalent daily, averaged over one week's consumption. Serum $\gamma$-glutamyltransferase $(\gamma-\mathrm{GT})$, a useful indicator of alcoholic liver damage, ${ }^{3}$ was estimated in women who had had blood taken for other purposes. Informed consent was obtaine for this procedure. All babies were born in the Warneford Hospital and routine neonatal examina tions were carried out by consultant paediatriciant and junior staff who did not know the drinking history. Details of the baby's gender, gestational age, Apgar score, birthweight, and head circumference were obtained from the neonatal case-notes together with information on congenital abnormalities, maternal age, and parity. Maternal height was not recorded.

\section{Results}

At booking, $15.7 \%$ of women were in the first trimester of pregnancy, $72 \%$ in the second, and $12.3 \%$ in the third. Results of fetal outcome were available in 973 of the 1000 pregnancies and are summarised in the Table. Twenty-seven women were lost to follow-up because they had moved from the $\rightarrow$ area while pregnant. Of the 973 women, 479 (49\%) said they had been non-drinkers during pregnancy, No $359(37 \%)$ said they had drunk between 1 and $10 \mathrm{ml}$ alcohol on average daily, $107(11 \%)$ between 10 요 and $20 \mathrm{ml}$ daily, and $28(3 \%)$ women had drunk over $\mathrm{\omega}$ $20 \mathrm{ml}$ daily. The highest reported consumption was $80 \mathrm{ml}$ daily and the baby was normal. There was no 0 association between alcohol consumption and the $\mathbb{\Phi}$ number of abortions (22), stillbirths (7), multiple $\stackrel{?}{+}$ pregnancies (10), nor between gender, gestational 
Table Alcohol consumption in pregnancy and fetal outcome

\begin{tabular}{|c|c|c|c|c|c|c|c|c|c|}
\hline & \multicolumn{9}{|c|}{ Alcohol intake $(\mathrm{ml} / 24 \mathrm{~h})$} \\
\hline & 0 & $1-10$ & $11-20$ & $21-30$ & $31-40$ & $41-50$ & $51-70$ & Over 70 & Total \\
\hline $\begin{array}{l}\text { No of cases } \\
\text { Outcome of pregnancy }\end{array}$ & $479(49 \%)$ & $359(37 \%)$ & $107(11 \%)$ & 14 & 4 & 5 & 4 & 1 & 973 \\
\hline $\begin{array}{l}\text { Abortions } \\
\text { Abremey }\end{array}$ & 11 & 6 & 4 & $\mathbf{0}$ & 1 & $\mathbf{0}$ & $\mathbf{0}$ & 0 & 22 \\
\hline Stillbirths & 4 & 3 & $\mathbf{0}$ & 0 & 0 & 0 & $\mathbf{0}$ & 0 & 7 \\
\hline Multiple live births & 5 & 3 & 2 & 0 & $\mathbf{0}$ & 0 & $\mathbf{0}$ & $\mathbf{0}$ & 10 \\
\hline Singleton live births & 459 & 347 & 101 & 14 & 3 & 5 & 4 & 1 & 934 \\
\hline Neonatal deaths & 1 & 4 & $\mathbf{0}$ & $\mathbf{0}$ & $\mathbf{0}$ & $\mathbf{0}$ & $\mathbf{0}$ & $\mathbf{0}$ & 5 \\
\hline Ma or congenital abnormalities & 0 & 6* & $\mathbf{0}$ & $\mathbf{0}$ & 0 & $\mathbf{0}$ & $\mathbf{0}$ & 0 & 6 \\
\hline
\end{tabular}

*Significant $\chi^{2}$ test, $P=<0.01$.

age, and Apgar score of the babies. There was no significant difference between the rate of neonatal deaths in drinkers and non-drinkers $\left(\chi^{2}\right.$ test, $P=0 \cdot 16$, Yates's correction for continuity was applied). The overall prevalence of smoking was similar in drinkers $(23.8 \%)$ and non-drinkers $(24.4 \%)$, but $46 \%$ of those drinking more than $20 \mathrm{ml}$ of alcohol smoked.

None of the 473 babies of non-drinking mothers had a major congenital abnormality, but $6(1.2 \%)$ of the 488 babies whose mothers admitted drinking alcohol did have congenital abnormalities. Two such abnormal babies were among those born to the 57 (3.5\%) mothers who admitted having had a 'binge' in early pregnancy. Comparison of this 'binge' group with the rest of the drinkers demonstrated that this apparently increased rate of abnormality was not significant ( $\chi^{2}$ test, $\mathbf{P}=\mathbf{0} \cdot 1$, Yates's correction for continuity was applied). The babies of nondrinkers had a significantly smaller rate of congenital abnormality when compared with the expected rate of $1.64 \%$ in south Warwickshire ( $\chi^{2}$ test, $\left.P=<0.01\right)$, whereas those who had been exposed to some alcohol in pregnancy had within the expected rate of abnormality.

The 6 major abnormalities were: iniencephaly; lumbosacral myelomeningocele; absent left ear (inner and middle ear included, confirmed by tomography); microcephaly associated with atrophy of the cerebral hemispheres and cleft palate; single cardiac ventricle with pulmonary stenosis and transposition of great vessels; multiple congenital abnormalities (agenesis of brain and kidneys,

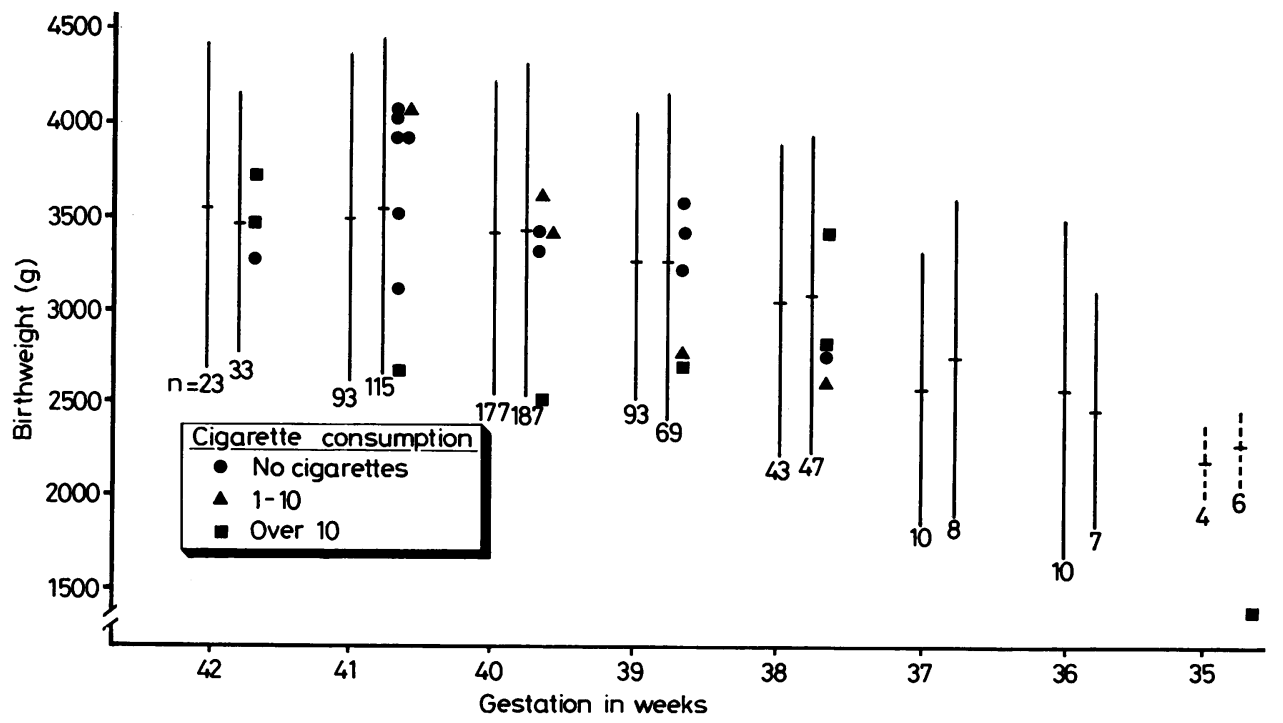

Fig. 1 Alcohol consumption in pregnancy and birthweight (mean $\pm 2 S D$ ). At each week of gestation the left line refers to infants of non-drinking mothers, the line on the right to infants of drinking mothers, and the symbols to individual babies of mothers drinking over $20 \mathrm{ml}$ alcohol daily. There were too few babies of 35 weeks' gestation to give meaningful standard deviation values. 


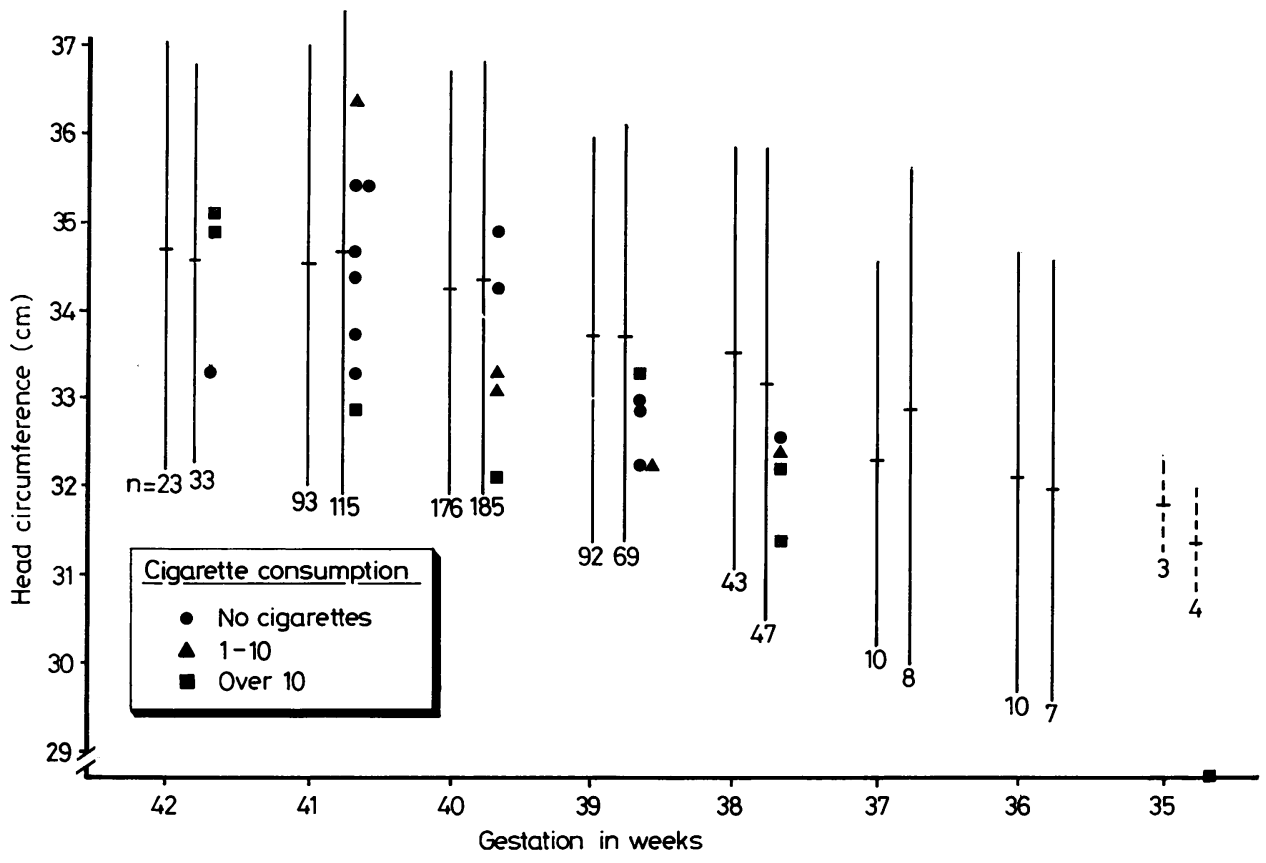

Fig. 2 Alcohol consumption in pregnancy and head circumference (mean $\pm 2 S D)$.

spina bifida, absent patellae, and pes valgus). Only one of the mothers of these babies smoked.

There were 15 minor congenital abnormalities, and their incidence was not associated with alcohol consumption. They were: hydrocele (4), congenital dislocation of the hip (2), undescended testis (2), accessory digits (2), urethral valves (1), accessory auricles (1), hooded prepuce (1), anal polyp (1), and pectus excavatus (1). Only 2 of the mothers of these babies were smokers. In no case of any abnormality was there a history of excessive coffee consumption in pregnancy. ${ }^{4}$

A comparison in birthweight and head circumference was made between the 458 singleton liveborn babies of non-drinkers, the 475 similar babies of all the drinking mothers, and the 26 babies of the heavier drinking mothers who drank over $20 \mathrm{ml}$ alcohol daily ( 1 infant of a diabetic mother was excluded from both the first and last of these groups). There was no significant difference in the distribution of social class $\left(\chi^{2}\right.$ test, $\left.P=0.86\right)$ or parity $(P=0.93)$ of the mothers but more of the heavier drinkers smoked.

The results are shown in Figs 1 and 2. There was no significant difference between the birthweight and head circumference of the babies whose mothers drank alcohol and the babies whose mothers did not. There was a trend however, towards smaller birthweight and head circumference in the babies whose mothers drank more than $20 \mathrm{ml}$ alcohol daily. The reduction in birthweight did not reach statistical significance, but the reduction in head circumference $\stackrel{\circ}{\circ}$ was significant in babies of 35,38 , and 39 weeks' gestation $(P=<0.001, \quad<0.01$, and $<0.05 \stackrel{\Omega}{\Rightarrow}$ respectively by $t$ test). At these gestational ages all the $\frac{0}{3}$ babies of the heavier drinkers had a head circum- $\frac{}{5}$ ference below that of the mean of non-drinkers' babies. In this group of heavier drinkers, the results are classified according to whether the mothers' cigarette consumption was nil, 1-10, or greater than 10 cigarettes daily. It was apparent that the heavy 3 . smokers tended to have the lighter babies with smaller head circumferences.

A total of 442 v-GT estimations was performed. Three results were abnormal: 42,109 , and $81 \mathrm{IU} / 1$ ? (normal range less than $30 \mathrm{IU} / \mathrm{l}$ ) from women $\frac{D}{0}$ reporting alcohol intakes of 22,7 , and $12 \mathrm{ml} /$ day respectively. The first 2 women had babies who were $N$ small-for-dates (that is below the 10th centile for $N$ gestational age) and the third had a missed abortion. 오

\section{Discussion}

Reliable estimates of alcohol consumption are $\frac{\infty}{\mathbb{D}}$ notoriously hard to obtain. Because the questionnaire was self-administered and because the questions on 
alcohol consumption were mingled with a number of other unrelated questions, we feel that the information on alcohol consumption is reasonably accurate. ${ }^{5}$

None of the women in this study consumed as much alcohol as in the report of Clarren and Smith. ${ }^{1}$ Nevertheless, consumption of over $20 \mathrm{ml}$ daily had a measurable association with adverse outcome of pregnancy. The association of a fairly small level of alcohol consumption with major congenital abnormality is striking. The association of raised serum $\gamma$-GT with abnormal fetal outcome in every case is also noteworthy.

The small number of cases does not allow us to make firm conclusions about any reduction in head circumference with alcohol consumption, but it would appear that some of the observed reduction is independent of smoking. As we have shown, those who drink heavily are more likely also to smoke. It is possible that the association of smoking with decreased birthweight may partly be due to alcohol consumption, as drinking habits have not been recorded in surveys of smoking in pregnancy. ${ }^{6}$ Only a larger study will clarify this issue.

It is not possible to state whether the relationship of alcohol intake and adverse outcome of pregnancy is causal, or whether it is due, for example, to an associated dietary or vitamin deficiency. Apart from complete abstention, no 'safe' level of alcohol consumption was found; even moderate 'social' drinking is associated with a risk of abnormal fetal outcome.

We thank Sister $\mathbf{J}$ Noon and her staff for their co-operation; Mrs R Harvey for clerical assistance; Dr J Robinson for the $\gamma$-GT-estimation; Dr J S Dodge for statistical advice.

\section{References}

1 Clarren S K, Smith D W. The fetal alcohol syndrome. N Engl J Med 1978; 298: 1063-7.

2 Ouellette E M, Roslett H L, Rosman N P, Weiner L. Adverse effects on offspring of maternal alcohol abuse during pregnancy. $N$ Engl J Med 1977; 297: 528-30.

3 Rosalki S B, Zilva J F. Serum $\gamma$-glutamyltransferase and alcoholism. Lancet 1977; ii: 1183-4.

4 Jacobson M F, Goldman A S, Syme R H. Coffee and birth defects. Lancet 1981 ; i: 1415-6.

5 Russell M, Bigler L. Screening for alcohol-related problems in an out-patient obstetric-gynecologic clinic. Am J Obstet Gynecol 1979; 134: 4-12.

6 Butler N R, Goldstein H, Ross E M. Cigarette smoking in pregnancy: its influence on birth weight and perinatal mortality. Br MedJ 1972; ii: 127-30.

Correspondence to Dr P J M Davis, 87 Radford Road, Leamington Spa, Warwickshire.

Received 9 September 1982

\section{British Paediatric Association}

$\begin{array}{ccc}\text { Annual meetings } & \\ 1983 & 12-16 \text { April } & \text { York University } \\ 1984 & 10-14 \text { April } & \text { York University } \\ 1985 & 16-20 \text { April } & \text { York University } \\ 1986 & 15-19 \text { April } & \text { York University } \\ 1987 & 7-11 \text { April } & \text { York Unievrsity }\end{array}$

